\title{
Space, scale, and regional inequality in provincial China: A spatial filtering approach
}

\begin{abstract}
:
This paper investigates regional inequality and development in China's Guangdong province by employing the multi-scale and multi-mechanism framework. Departing from previous studies in which the relationship between spatial dependence and regional inequality tends to be self-evident, we apply a spatial filtering method that eliminates spatial dependence of the data and quantifies the extent to which spatial effects have contributed to regional inequality at multiple scales. The results suggest that over $90 \%$ of the divide between the core of the Pearl River Delta (PRD) and the periphery areas of Guangdong province can be explained by the effect of strengthening spatial autocorrelation. By incorporating spatial filters in space-time models, we further reveal the space-time and core-periphery heterogeneities of development mechanisms. Our study confirms that the integration of a multi-scale and multi-mechanism framework and rigorous spatial analysis methods, such as spatial filtering and space-time modeling, helps better understand the spatial and temporal complexity of regional development in China.
\end{abstract}

Keywords: regional inequality, multi-scale and multi-mechanism, spatial filtering, spacetime, spatial dependence, Guangdong, China 


\section{Introduction}

Since the early 1990s, driven by the theoretical advances in new economic geography, new endogenous growth, and new convergence (Krugman, 1991; Barro \& Sala-i-Martin, 1997; Martin \& Sunley, 1998; Scott \& Storper, 2003), regional inequality has received renewed interdisciplinary interests. Regional inequality also attracts considerable interests from policy makers and governments because the growing interregional inequality is often associated with political and ethnic tensions and becomes a potential threat to national unity and social cohesion (Wei, 2000; Kanbur \& Venables, 2005). Cross-country analysis has found that globalization and trade liberalization may bring wealth to poor regions in developed countries (Ezcurra \& Rodríguez-Pose, 2013). In contrast, inequalities in many developing countries tend to persist, and new forms of uneven regional development are emerging (Lessmann, 2013; Ezcurra \& Rodríguez-Pose, 2013a).

The rapid economic growth of China in the era of reform is undoubtedly associated with a spatially uneven development, attracting considerable attention from both scholars and policy makers. Although the majority of studies have been focused on the evolution of regional inequality among Chinese provinces and groups of provinces (e.g., Wei, 2002; Lu \& Wang, 2002; Fan \& Sun 2008; Li \& Wei, 2010; Li \& Fang, 2014), the research frontier on the regional inequality in China has recently extended to intraprovincial analysis of inequalities using finer-scale data (Yu \& Wei, 2008; Wei \& Ye, 2009; Li \& Wei, 2014). Case studies in Zhejiang, Jiangsu, and Guangdong have documented the spatial and temporal complexity of regional inequality under Chinese provinces (e.g., Wei \& Ye 2009; Wei et al., 2011; Liao \& Wei, 2012). Notably, this strand of literature has been particularly fueled by recent developments in GIS spatial analysis methods and has supplied more detailed evidence about the role played by space and scale in shaping the unevenness of development in China (e.g. Wei \& Ye, 2009).

This paper examines regional inequality and development in China's Guangdong province, known for the geographical concentration of development in the core region of the Pearl River Delta (PRD). In doing so, the study aims to further examine the relationship between space, scale, and regional inequality in provincial China based on the multi-scale and multi-mechanism framework. Specifically, it applies an alternative approach, namely, spatial filtering, to handle spatial dependence. Although previous studies have addressed the same issue using exploratory spatial data analysis (ESDA) and geographically weighted regression (GWR), the application of a spatial filtering approach has its own advantages: on the one hand, this method is rather straightforward and allows us to quantitatively clarify the relationship between spatial dependence and regional inequality; on the other hand, as argued by Thayn and Simanis (2013), spatial filtering offers a highly powerful and flexible way to reduce misspecification errors in linear regression models. Therefore, by incorporating spatial filters in a set of space-time modeling specifications, we can more accurately probe the space-time heterogeneities of development mechanisms, uncovering the varying effects of the same mechanism on regional development over space and time.

\section{Literature review}

Regional inequality has generated lasting debates among adherents of various schools of development (e.g., convergence, divergence, and inverted-U). Kuznet (1955) 
and Williamson (1965) argued that when countries develop from agricultural economies to industrial economies, spatial inequality tends to initially increase, and then it peaks and decreases following an inverted-U trajectory (Lessmann, 2013, 2014). Since the early 1990 s, new convergence theory has become more influential in the literature. Drawing from two important notions, namely, the $\beta$ and $\sigma$ convergences, Barro and Sara-I-Martin (1991) identified that poorer states or regions in the US and Western Europe grew faster, resulting in convergence over the long run.

Growing concerns about the spatial influences of economic globalization and political or fiscal decentralization have been witnessed in the recent years (e.g., Ezcurra \& Rodríguez-Pose, 2013a, 2013b; Lessmann, 2013, 2014). For instance, Lessmann (2014) presented new evidence that supports the inverted-U hypothesis using a panel data of 56 countries over the period 1980-2009. The study also showed that within a group of very high-income countries, regional inequality actually increases again, and this increase may be related to the countries' shift from manufacturing industries to service sectors. Reforms in former socialist countries and transitional economies have drawn even more attention to the spatial influences of reforms. In this context, the role of space and scale in shaping the evolution of regional inequality is emphasized by scholars, challenging the traditional convergence, divergence or inverted-U hypotheses (e.g., Wei, 1999; Wei \& Ye, 2009).

China's market reform and spectacular economic growth have generated considerable scholarly attention on the issue of regional inequality, deepening our understanding of the evolution of regional inequality in a transitional economy (e.g., Wei, 1999; Lu \& Wang, 2002; Fan \& Sun, 2008; Li \& Gibson, 2013). More specifically, the multi-scale and multi-mechanism framework has been proved as a valuable framework. On the one hand, regional inequality is sensitive to geographical scales. Ignoring scales may result in controversial findings on regional inequality (Wei, 2002). For instance, Li and Wei (2010) clarified that although the divide between coastal and inland provinces has risen, the interprovincial inequality in China has actually fluctuated significantly since the late 1990s (p. 3). Recent efforts have further "scaled down" the research on regional inequality in China by examining regional inequality within individual provinces. These efforts argue that within provinces, regional inequality in China can also be differentiated on interregional (between-region), intermunicipality (between-city) and intercounty (between-county) scales.

On the other hand, major drivers of regional development in China can be conceptualized into a triple process of economic transition, namely, globalization, marketization, and decentralization, acting as structural forces behind regional inequality in China at multiple scales (Wei, 2000; Wei, 2002). First, during the reform era, the central government has granted more decision-making power to local governments (decentralization), providing local states with more incentives to promote economic growth (Wang, 2010). Second, under market reform, the state-owned sector has exerted less control over the economy in China, whereas the private sector has become an important driver and a new growth momentum (marketization) (Wei, 2004). Together with decentralization and marketization, globalization is the process in which China has been increasingly integrated with the world economy, making the country one of the largest recipients of foreign direct investment (FDI) in the world. Lastly, under the triple process of economic transition, coastal localities have developed at a fast pace based on 
the growth of non-state-owned enterprises (SOE) and the agglomeration of external capital. In contrast, those provinces or regions favored by socialist planning and dominated by state-owned enterprises have fallen behind, resulting in widening gaps between coastal and inland regions and localities (Wei et al., 2011; Hao \& Wei, 2010).

Notably, recent studies of regional inequality in China have greatly benefited from the applications of newly developed GIS spatial analysis methods. First, using GIS spatial analysis techniques has been useful in identifying the emerging regions and clusters and in examining their contribution to changing patterns of regional inequality (Ye \& Wei, 2005). Using ESDA, studies in Zhejiang demonstrated that the rising intercounty inequality could be attributed to the spatial clustering of development in areas centered on Hangzhou and Wenzhou (Wei \& Ye, 2009; Yue et al., 2014). Second, consistent with the broad literature on the pervasive force of agglomeration, the application of rigorous spatial analysis techniques has found strong evidence for spatial dependence and agglomeration, which has intensified regional inequality at both the interprovincial and intra-provincial levels in China. For instance, applying spatial Markov chains, researchers demonstrate that neighboring counties matter for a county's development status, and then self-reinforcing spatial dependence has strengthened the north-south divide in Jiangsu and the core-periphery disparity in Guangdong (Wei et al., 2011; Liao \& Wei, 2012).

Additional research is still necessary as found by the literature review. First, in the existing literature, the relationship between spatial dependence and regional inequality in provincial China tends to be self-evident. Limited quantitative investigation has been performed on the extent of contribution of spatial dependence to regional inequality at different geographical scales. Second, the triple process of economic transition has been proven as a fundamental cause of the inland-coastal income inequality during the reform era (e.g., Hao \& Wei, 2010). Nevertheless, the different effects of these mechanisms on the regional development within provinces have not been thoroughly examined. Third, with a few exceptions (e.g. Lu \& Wei, 2007; Liao \& Wei, 2012; Yuan \& Wu, 2013), studies on regional inequality in Guangdong mainly dealt with the regional development in the 1990s (Gu et al., 2001). Changes in the development mechanisms since the 2000s deserve more research efforts. By integrating a spatial filtering approach and the multiscale and multi-mechanism framework, this paper emphasizes the exact relationships among spatial dependence, scale, and regional inequality. The case of Guangdong, a province known for being "one step ahead" in China's economic transition, also sheds further light on the spatial-temporal heterogeneities of development mechanisms in different stages of the reform.

\section{Research setting: Guangdong province}

As shown in Fig. 1, Guangdong is located in southeastern China and consists of four sub-regions, including the core region of the PRD, North Guangdong, West Guangdong, and East Guangdong. Twenty-one municipalities as well as 81 counties and cities make up Guangdong as of 2012. The province has a land area of 179,612 square kilometers (approximately $2 \%$ of China's territory), and a total population of 105.9 million in 2012. The core region is called the PRD, which is adjacent to Hong Kong (Fig. 1). The region is also known as an economic powerhouse in China that is driven by the 
development of export-oriented manufacturing and a major flow of investment from Hong Kong and Taiwan (Lin, 2009).

(Fig. 1 about here)

Regional development in Guangdong has benefited from the reform policy in China launched in 1978. The geographic location of Guangdong is notably distant from the political and economic center of the country to the north (Lin, 1997). In the period of state socialism under Mao, Guangdong had not been a favorable destination for the state capital, and the province has been historically known for its globally ethnic connections with the Chinese diaspora in North America, Europe, and South East Asia. As Lin (2009) summarized, the geographical proximity of Guangdong to Hong Kong and its ties with overseas Chinese investors have allowed the province to move "one step ahead" in China's reform and to become a favorable laboratory in experiencing reforms and opening up (gaige kaifang). The leading role of Guangdong in the economy of China can be manifested by its rapid economic growth over the past three decades, with an annual growth rate of $13.3 \%$ as compared to the $9.2 \%$ growth rate at the national level (GSB, 2013). In terms of the size of the economy, the rank of Guangdong among 31 provincial units in China rose from fifth in 1978 to first in 1990, and the province has continuously been the largest provincial economy since then.

Whereas Guangdong has achieved spectacular economic growth in the reform era, regional development in the province is clearly characterized by a spatially uneven pattern. The PRD region accounts for $30.5 \%$ of the land area in the province, but it produced $76.6 \%$ of the GDP of Guangdong in 2012 as compared to $55.5 \%$ in 1990, and it has dominated in the FDI and exports of the province (Table 1).

(Table 1 about here)

Using the multi-scale and multi-mechanism framework, the following sections will analyze the spatial dependence of county-level GDP per capita (GDPPC) in Guangdong and will further investigate the spatial effects on the scale and dynamics of regional inequality at multiple scales as well as the spatial-temporal heterogeneities of development mechanisms. Most of the data used are compiled from the Guangdong Statistical Yearbook, and the GDP data are adjusted to the constant price in 1990. GDPPC is commonly used as an indicator of the overall level of economic or regional development (Fan \& Sun, 2006; Li \& Wei, 2010). The population data in non-census years were interpolated using census data from 1990, 1995, 2000, 2005, and 2010 because residence registration for the population tends to exaggerate the extent of inequality in China (Chan \& Wang, 2008; Li \& Gibson, 2013).

\section{Spatial dependence of county-level per capita GDP in Guangdong}

A major contribution of this study is quantifying the exact relationships among spatial dependence, scale, and regional inequality using a spatial filtering method. Before presenting the results of spatial filtering-based analyses, this section applies an ESDA approach, in particular global and local Moran's I statistics, to investigate the spatial dependence of county-level GDPPC in Guangdong. 
In calculating the Moran's $I$, the spatial weight matrix is particularly considered because it represents the specific spatial links among spatial units (Anselin, 1988).

Investigating the alternative weighting strategy is appropriate because of the complexity of spatial interactions. Following Yu and Wei (2008) and Li and Fang (2013), we use five spatial weight metrics to reveal the significance of Moran's I. As shown in Table 2, the resulting Moran's $I$ values over the study period are all higher than 0 and significant at a level of 0.001, indicating the significance of spatial dependence in the county-level GDPPC data.

(Table 2 about here)

Table 3 presents changes of Moran's I values in Guangdong. The Moran's I indicator under the contiguity strategy rose consistently from 0.44 in 1988 to 0.53 in 2012, revealing the existence of a positive spatial dependence and a strengthening global spatial autocorrelation since the early 1990s.

\section{(Table 3 about here)}

As Yu and Wei (2008) stated, two scenarios are possible when an upward Moran's $I$ is observed. First, new clusters may exist. Second, more areas become similar. By considering these scenarios, Local indicators of spatial association (LISA) Moran's I can supplement the global Moran's $I$ index in detecting the sources of global spatial autocorrelation. As demonstrated in Fig. 2, LISA maps in 1988 and 2012 reflect the agglomeration of development in the PRD. Therefore, the rise of global Moran's I can be attributed to the increased spatial similarity among counties in the PRD instead of the formation of new clusters out of the PRD. It also implies that the spatial dependence should be considered in our analysis.

(Fig. 2 about here)

When dealing with spatial dependence, spatial filtering can specifically remove the spatial dependence so that the studied variables, which are initially spatially correlated, can be divided into spatial and non-spatial components. Although different filtering methods can be used (Getis \& Griffith, 2002), we opted for Griffith's spatial filtering approach because it can be easily incorporated in the specifications of other regression models, such as panel data framework (Patuelli et al., 2011), and it can also be used to furnish a space-time model (Griffith, 2008).

The selection of spatial filters is based on the computational formula for the Moran's I statistic. This methodology uses eigenvector decomposition techniques, which extract the orthogonal and uncorrelated numerical components from an $N \times N$ modified spatial weight matrix:

$$
w=\left(\mathbf{I}-\frac{11^{T}}{n}\right) C\left(\mathbf{I}-\frac{11^{T}}{n}\right)
$$

where $C$ is an $n \times n$ binary geographic connectivity matrix, I is an $n \times n$ identity matrix, $\mathbf{1}$ is an $n \times 1$ vector containing ones, and $T$ is the matrix transpose (Getis \& Griffith, 2002). 
The eigenvectors of the modified matrix are calculated to maximize the sequential Moran's I values. The first computed eigenvector E1 results in the largest Moran's I value among all eigenvectors of the modified matrix, followed by the second eigenvector E2, which is a set of numbers that aim to maximize the Moran's $I$ value while being orthogonal and uncorrelated with E1. The process continues until $N$ eigenvectors have been computed. The final set of these eigenvectors includes all possible mutually orthogonal and uncorrelated map patterns (Getis \& Griffith, 2002; Thayn \& Simanis, 2013). When these eigenvectors are used as regressors, they could be treated as proxies for missing explanatory variables that capture the underlying geographical structure (Patuelli et al., 2011). Using all $N$ eigenvectors in a regression framework is notably undesirable because of issues related to model parsimony and statistical significance and is often impossible to add with other covariates. Therefore, a smaller subset of candidate eigenvectors can be selected from the $N$ eigenvectors based on their Moran's $I$ values. In this study, candidate eigenvectors are selected based on their Moran's $I$ values and their correlations with the geo-referenced GDPPC data using a minimum threshold of 0.5 for the Moran's I statistic.

The results of spatial filtering show that the spatial dependence of county-level GDPPC in Guangdong has been effectively removed (see the columns of the filtered data in Table 3). The positive Moran's I statistics obtained with the actual data are not only reduced drastically, but they also become negative and are statistically insignificant. In other words, incorporating a set of judiciously selected eigenvectors results in the filtering of spatial autocorrelation from the original county-level GDPPC data. As a result, two sample series were obtained: one with actual data and another with filtered data. For the rest of this study, we examine the multi-scalar characteristics and the dynamics of regional inequality with two sample series; this investigation means that the only differences between them are assumed to be attributed to spatial dependence.

\section{Analyzing scales and dynamics of regional inequality with spatial filtering}

Regional inequality can be measured by a variety of indices such as GINI, Theil, and the coefficient of variation (CV). First, in Fig. 3, we estimate regional inequalities in Guangdong using population-weighted coefficient of variation (WCV, see Petrakos et al., 2005 for the advantages of WCV as compared to CV). As shown in Fig. 3, regional inequality is sensitive to spatial scales. More intensive disparities exist in more disaggregated geographical scales. For the spatially filtered data, the extent of regional inequality at the regional level remains smaller than those at the municipality and county levels. Using the Theil and GINI indexes, we further illustrate through Table 4 that over $90 \%$ of the inequality at the regional level could be attributed to spatial dependence, whereas the influence declines to around 50\%-70\% at the municipal level and approximately $30 \%-50 \%$ at the county level. These findings suggest that regional inequality has been evidently reinforced by spatial dependence, whereas the association between spatial effects and regional inequality is apparently sensitive to scales. Second, the recent decreasing trends are more stable in the case of filtered data (Fig. 3). In the case of Guangdong, factors contributing to spatial dependence have promoted divergence because the differences in the evolution of regional inequalities between the original and filtered data are attributable to spatial dependence. Third, regional inequalities at all scales tend to increase in the early 1990s and to decrease slightly until the end of 1990 , 
partly because of the industrialization and urbanization of some rural counties outside of large cities (Lin, 2009). The inequality rose again in the early 2000s and then declined afterward. A possible explanation can be the influx of FDI triggered by China's accession to the World Trade Organization (WTO) in the early 2000s, which strengthened uneven regional development in Guangdong because FDI locations are characterized by pathdependent and spatial agglomeration ( $\mathrm{Ng} \&$ Tuan, 2003). Nevertheless, given the increased cost of production and tightening environmental regulation in the PRD in recent years, manufacturing activities have started to relocate from the PRD to the peripheral region (Liao \& Chan, 2011). In addition, a series of policies implemented by the provincial government (Liao \& Wei, 2012), which attempts to reduce the gap between the PRD and the rest of the province, may have some positive effects. In short, the evolution of regional inequalities is strongly tied to the dynamic interactions among government policies, external capital, and localities in Guangdong and can hardly be simplified into convergent, divergent, or inverted-U trajectories.

(Fig. 3 \& Table 4 about here)

To shed further light on the dynamics of regional inequalities in Guangdong, Fig. 4 maps the changes of relative GDPPC growth using both actual and spatially filtered county-level GDPPC data. As Fig. 4 illustrates, many counties that are distant to the periphery of the PRD have been diverging from below. In other words, they fell further behind the provincial average. Counties moving upward are those areas geographically closer to the PRD. In contrast, the map based on spatially filtered data has suggested a peculiar pattern of convergence or divergence (Fig. 4b). More counties in the periphery region have "converged" to the provincial average, and counties in the PRD are less likely to forge ahead or to become richer as compared with their counterparts, based on the actual data. These results indicate that space plays a decisive role in regional convergence or divergence in Guangdong.

(Fig. 4 about here)

Although the mapped changes in GDPPC are informative, they do not identify underlying dynamic regularities in the data. We thus turn to the stochastic kernel representation of intra-distribution dynamics. Similar to Markov chains, stochastic kernel densities are the continuous version of the model of distribution dynamics (Fischer \& Stumpner, 2008). As shown in equation (2), $F_{t}$ denotes the cross-sectional distribution of GDPPC at time $t$, and then the distribution evolves according to the following:

$$
F_{t+1}=M F_{t}
$$

where $M$ denotes the distribution from time $t$ to time $t+1$, tracks where the points in $F_{t}$ end up in $F_{t+1}$, and can be viewed as a stochastic kernel or transition function that describes the (time-invariant) evolution of the cross-sectional distribution in time.

Following Fischer and Stumpner (2008), we use the stochastic kernel approach and estimate the highest density plots using a 5-year transition period. The highest density plot is defined as "the smallest region of the sample space containing a given 
probability" (Maza \& Villaverde, 2009). Thus, each vertical strip in Fig. 5 denotes the conditional density of a GDPPC level in time $t$. For any point $y$ on the axis for period $t$, considering the direction parallel to the $t+5$ time-axis traces out a conditional probability density. Fig. 5 particularly shows the highest density regions for probabilities of $25 \%$, $50 \%, 75 \%$, and $99 \%$ as it passes from a darker area to a lighter area. In addition, the figure illustrates as a bullet the mode (value of GDPPC in time $t+5$, where the density function takes on its maximum value) for each conditional density of every GDPPC in time $t$. Similar to a transition matrix based on Markov chains (Liao \& Wei, 2012), the 45degree diagonal in the graph indicates persistent properties. Therefore, most of the densities are concentrated along this diagonal, and the elements in the cross- sectional distribution remain where they started.

(Fig. 5 about here)

On the one hand, as illustrated in Fig. 5, a large proportion of the probability mass tends to remain agglomerated along the main diagonal over the 5-year horizon, and the poorest counties have been clearly facing more challenges to move upward. On the other hand, we find that some counties that are well above average decline in the intradistribution shape, which is consistent with the recent decline in regional inequalities among counties. The plot based on spatially filtered data reveals conspicuously spatial effects on convergence or divergence in Guangdong (Fig. 5b), which mainly suggests that if spatial dependence is eliminated, then the upward mobility of these highly affluent counties is constrained, and the gap between the rich and poor tends to narrow.

\section{Space-time modeling of multi-mechanism}

The above-mentioned sections compare spatially filtered and actual data to investigate the effects of spatial dependence on the scales and dynamics of regional inequality in Guangdong. To better understand the driving forces of uneven development, we use a spatial filtering-based panel regression and space-time models, which enable us to detect the detailed spatial and temporal heterogeneities of underlying mechanisms.

\section{Underlying mechanisms of regional inequality}

We treated the GDPPCs of the individual years as dependent variables (Li \& Fang, 2014; Yu \& Wei, 2008), and five time-points, namely, 1990, 1995, 2000, 2005, and 2010 were included in our panel dataset given the availability of data. The independent variables selected for this study are broadly similar to those used in the previous literature on regional development in Zhejiang (Wei \& Ye, 2009), Jiangsu (Wei \& Kim, 2002) and Beijing (Yu \& Wei, 2008). They are also based on the conceptualization of regional development in China as a triple process of marketization, globalization, and decentralization.

1. The foreign direct investment per capita (FDIPC) is selected as a proxy of the effect of globalization. It is assumed to positively contribute to the regional development in Guangdong.

2. The importance of socialist institutions and the infusion of market mechanisms can be represented by the share of non-SOEs in employment (NSOEPCT). 
3. The decentralization process is represented by the ratio of local governmental expenditure per capita to the provincial government's budgetary spending per capita (GOVPC). It is a proxy of the degree of fiscal decentralization and the shift of power from upper level governments to local governments (Hao \& Wei, 2010; Wang, 2010).

4. The fixed asset investment per capita (FIXPC) is selected as the primary factor of input in regional development. In China, fixed investment is also considered as a key instrument in the process of industrialization and economic growth. FIXPC is expected to positively contribute to regional development.

5. The agglomeration economies such as urbanization economies are widely acknowledged as key drivers of economic growth (Jacobs, 1969). As noticed by scholars (Chen \& Partridge, 2013), China's regional development policy leans toward the urban area, and urbanization has been considered as an engine of regional development. We use the percentage of urban population in the total population (URB) to investigate the role of urbanization in the development in Guangdong.

\section{Model specifications}

We build our model based on the production function, which formally expresses the output of an economic system as the product of basic input factors, and all the input factors are hypothesized to be exogenous inputs (Yu \& Wei, 2008). Therefore, a production function-like model for regional development mechanisms can be specified as the following:

$$
\mathrm{GDPPC}=\mathrm{A}^{*} \mathrm{FDIPC}^{\beta 1} * \mathrm{GOVPC}^{\beta 2} * \mathrm{NSOEPCT}^{\beta 3} * \mathrm{FIXINV}^{\beta 4} * \mathrm{URB}^{\beta 5}
$$

The exponential form can be transformed into a linear form through logarithmic transformation, which results in the familiar linear model:

$$
y_{i t}=\beta_{i t} X_{i t}+\varepsilon_{i t}
$$

where $y_{i t}$ is the logarithm-transformed GDPPC in county $i$ in year $t, X i t$ is the matrix containing a constant term and the five independent variables in their logarithmtransformed forms, $\beta_{i t}$ is the vector of model coefficients, and $\varepsilon_{i t}$ is the error term. After the transformation, all the variables are asymptotically normally distributed. Following Griffith (2008), we further incorporate spatial filters in equation (2) to construct a spatially structured random effect panel data model. Therefore, equation (4) becomes the following:

$$
y_{i t}=\beta_{i t} X_{i t}+s f_{i t}+\varepsilon_{i t}
$$

where $s f_{i t}$ is the linear combination for county $i$ in time $t$ of the selected spatial filter components, assuming that spatial dependence is specific to individual year $t$. As mentioned above, a subset of "candidate" eigenvectors have been selected and treated as regressors in equation (5). An AIC-based stepwise regression approach is used to select an optimal set of eigenvectors (or spatial filterers), capturing the inherent spatial dependence in a regression system. 


\section{Spatial filter-based panel data model}

We first estimated both the models of the OLS and the spatial filtering-based panel regression using county-level socioeconomic data in 1990, 1995, 2000, 2005, and 2010. Table 5 reports the overall pseudo- $\mathrm{R}^{2}$ and Moran's $I$ of the residuals as well as year-specific filters that can account for spatial dependence in the data. The results show that the spatial filtering panel regression model has removed almost all of the residual spatial dependence and has further increased pseudo- $\mathrm{R}^{2}$ values (Table 5).

\section{(Table 5 about here)}

Table 6 presents the results based on pooled OLS regression and spatial filtering panel regression (equation (5)). Multicollinearity is not a problem as VIF estimates are all lower than 2.5. From the results, at least three interesting findings emerge (Table 6). First, as measured by BIC, the spatial filtering model specification reports better fitting statistics in comparison to the simple pooled OLS model, which explains $77.2 \%$ of the total variance of the county-level GDPPC. Results of likelihood ratio tests also identify a significant reduction in deviance. Second, Table 6 shows that variables representing decentralization, marketization, and globalization are significant drivers of regional development in Guangdong, and investments as well as urbanization have a significantly positive influence on the development status of a county. In comparison with those in the pooled OLS model, the $t$ values of the coefficients for GOVPC and NSOEPT decrease. More importantly, FDIPC, reflecting globalization, is insignificant in the pooled OLS model, but its coefficients are positively significant in the spatial filtering panel regression model. The result of the OLS regression showing that the globalization force is not active in the regional development of Guangdong is contradictory to the nature of regional development in the province, where economic development has been driven by the inflow of FDI from overseas Chinese economies (Zhao et al., 2012). Therefore, the spatial filtering panel regression model, while considering spatial dependence, results in a more reliable estimation of these development mechanisms.

\section{(Table 6 about here)}

\section{Space-time models}

As Li and Wei (2010) argued, many agents of regional development in China are sensitive to the transitional nature of the reform. To achieve a more nuanced understanding of the temporal changes of the development mechanisms in Guangdong, we added five time dummies and time-specific terms to equation (5) and derived the following space-time model:

$$
y_{i t}=\beta_{0, t} I_{i t}+\beta_{1, t} x_{i t}+s f_{i t}+\varepsilon_{i t}
$$

where $y_{i t}$ denotes the GDPPC of county $i$ in time $t ; I_{i t}$ denotes the binary indicator variable of time $t$ for county $i ; x_{i t}$ denotes the triple process of economic transition, including FDIPC (globalization), GOVPC (decentralization) and NSOEPT

(marketization); $\beta_{0 t}$ represents the regression coefficients for the temporal dummies; and 
$\beta_{1, t}$ denotes the regression coefficients for covariates of FDIPC, GOVPC, and NSOEPT in time $t$.

Fig. 6 shows the temporally varying or time-specific coefficients of the three independent variables of FDIPC, GOVPC, and NSOEPT. Consistent with the results of Griffith (2008), incorporating spatial filters in these regression models substantially reduces the standard errors of these coefficients as compared to the results of the OLS regression. The simple pool OLS regression reveals a conspicuous decrease in the coefficients of FDIPC in 1990-2010. However, the models with spatial filters confirm that coefficients of FDIPC increased especially in the early 2000s, right after the entry of China into the WTO. The coefficients related to marketization have changed from negative to positive, indicating the addition of this mechanism in the development of Guangdong since the early 1990s.

(Fig. 6 about here)

The model based on equation (6) can be further expanded by considering the core-periphery structure in Guangdong (Liao \& Wei, 2012). Following Cravo and Resende (2013), we add two spatial regimes in the space-time model (equation (6)). The space-time regression model can be expressed as follows:

$$
\left[\begin{array}{l}
y_{i t, c} \\
y_{i t, p}
\end{array}\right]=\left[\begin{array}{llll}
x_{t, c} & y_{t, c} & & \\
& & x_{t, p} & y_{t, p}
\end{array}\right]\left[\begin{array}{l}
\beta_{i t, c} \\
\beta_{i t, p}
\end{array}\right]+s f_{i t}+\varepsilon_{i t}
$$

where $\beta_{i t, c / p}$ denotes the specific coefficients of covariates for counties in the core or periphery region in time $t$. The core region refers to the PRD, whereas the periphery region includes those counties in the areas outside of the PRD.

Fig. 7 presents the resulting spatially and temporally varying coefficients in the core and periphery regions. Clearly, the triple process of economic transition has played an important role in the regional development of the PRD, and then it caused the evident divide between these two regions. However, we also find that the coefficients of FDIPC, NSOEPT, and GOVPC for the periphery region continuously increased, indicating that the triple process of economic transition has been spreading toward the periphery areas in Guangdong. Interestingly, the coefficients reflecting marketization in the PRD declined, suggesting that the market reform tends to be less influential in the recent development of the core, where socialist market reform has been initiated much earlier than the periphery.

(Fig. 7 about here)

\section{Conclusion}

This study investigates regional inequality and development in China's Guangdong province, following the multi-scale and multi-mechanism framework. By applying a technique that has been rarely applied in previous studies, that is, spatial filtering, the study advances the literature by quantifying the exact relationships among spatial dependence, scale, and regional inequality. Based on the development of a set of spatial filtering-based space-time models, the research also demonstrates the detailed 
spatial-temporal heterogeneities of development mechanisms underlying the uneven regional development in Guangdong.

The multi-scalar analyses with spatial filters have yielded important findings. The results indicate that spatial dependence has strengthened regional inequality. In the case of Guangdong, spatial effects have accounted for more than $90 \%$ of the divide between the core region of the PRD and the rest of the province and for approximately $60 \%$ of the intermunicipality inequality. At the county level, $40 \%$ of the regional inequality can be explained by the strengthening spatial similarity of the development status in nearby counties. Furthermore, we have found that space also matters for regional convergence as spatial effects have contributed to a "poverty trap" in the periphery region, which is distant to the core region of the PRD. Our study has offered detailed empirical evidence that is consistent with the new economic geography model (Krugman, 1991) while treating geography in a more realistic manner (Bosker et al., 2010). The results also clarify that the geographical concentration of development in specific localities may have different effects on inequalities at different scales. For instance, new clusters in the periphery region should help reduce the core-periphery divide, but they may lead to the rise of between-county inequality. Therefore, policies toward inequality reduction should consider the scale of regional inequality that is focused on.

Our space-time models using spatial filters have enabled us to analyze data of geographically dependent units while controlling for inherent spatial dependence. More importantly, incorporating time dummies and spatial regimes has made it possible to detect such detailed space-time and core-periphery heterogeneities of the multimechanism. The results suggest that the triple process of economic transition tends to have stronger influences on the regional development in the PRD. An increased importance of these mechanisms for the development in the periphery has been witnessed in recent years, with marketization being increasingly embedded with other mechanisms in the PRD. These results demonstrate promising aspects of the application of space-time modeling techniques in the research on regional development in China.

From a methodology perspective, removing the spatial dependence from the original data allows for comparisons between the spatially filtered data and the actual data. In doing so, we quantify the spatial effects to some extent in a highly flexible manner (Thayn \& Simanis, 2013). More specifically, spatial filters can be added to many statistical packages and in different model specifications. Recent research has shown that spatial and temporal autocorrelation can be considered simultaneously by using spacetime filters (Griffith, 2008). Future improvements could focus on two aspects: 1) incorporating spatial filters in a geographically and temporally weighted regression framework to address the issues related to continuous spatial-temporal heterogeneity and 2) comparing the effectiveness of spatial filters in different regression models to support the application of spatial filtering models in different research domains. 


\section{References:}

Akita, T. (2003). Decomposing regional income inequality in China and Indonesia using two-stage nested Theil decomposition method. The Annals of Regional Science, 37 (1), 55-77.

Anselin, L. (1988). Spatial econometrics: Methods and Models. Dordrecht: Kluwer Academic Publishers.

Barro, R. J., \& Sala-i-Martin, X. (1991). Convergence across States and Regions. Brookings papers on economic activity, 1991 (1), 107-182.

Barro, R. J., \& Sala-i-Martin, X. (1997). Technological Diffusion, Convergence, and Growth. Journal of Economic Growth, 2 (1), 1-26.

Bosker, M., Brakman, S., Garretsen, H., \& Schramm, M. (2010). Adding geography to the new economic geography: bridging the gap between theory and empirics. Journal of Economic Geography, 10 (6), 793-823.

Chan, K. W., \& Wang, M. (2008). Remapping China's regional inequalities, 1990-2006: A new assessment of de facto and de jure population data. Eurasian Geography and Economics, 49 (1), 21-55.

Chen, A. (2010). Reducing China's regional disparities: Is there a growth cost? China Economic Review, 21 (1), 2-13.

Chen, A., \& Partridge, M. D. (2013). When are cities engines of growth in China? Spread and backwash effects across the urban hierarchy. Regional Studies, 47 (8), 13131331.

Cravo, T. A., \& Resende, G. M. (2013). Economic growth in Brazil: A spatial filtering approach. The Annals of Regional Science, 50 (2), 555-575.

Elhorst, J. P. (2003). Specification and estimation of spatial panel data models. International Regional Science Review, 26 (3), 244-268.

Ezcurra, R., \& Pascual, P. (2008). Fiscal decentralization and regional disparities: Evidence from several European Union countries. Environment and Planning A, 40 (5), 1185-1201.

Ezcurra, R., \& Rodríguez-Pose, A. (2013a). Does Economic Globalization affect Regional Inequality? A Cross-country Analysis. World Development, 52, 92-103.

Ezcurra, R., \& Rodríguez-Pose, A. (2013b). Political decentralization, economic growth and regional disparities in the OECD. Regional Studies, 47 (3), 388-401.

Fan, C. C., \& Sun, M. (2008). Regional Inequality in China, 1978-2006. Eurasian Geography and Economics, 49 (1), 1-20.

Fischer, M. M., \& Stumpner, P. (2008). Income distribution dynamics and cross-region convergence in Europe. Journal of Geographical Systems, 10 (2), 109-139.

Getis, A., \& Griffith, D. A. (2002). Comparative spatial filtering in regression analysis. Geographical analysis, 34 (2), 130-140.

Griffith, D. A. (2008). A comparison of four model specifications for describing small heterogeneous space-time datasets: Sugar cane production in Puerto Rico, 1958/59-1973/74. Papers in Regional Science, 87 (3), 341-355.

Guangdong Statistical Bureau (GSB). (2013). Guangdong statistical yearbook, 2013. Beijing, China: China Statistics Press.

Gu, C., Shen, J. F., Wong, K. Y., \& Zhen, F. (2001). Regional polarization under the socialist-market system since 1978: a case study of Guangdong province in south China. Environment and Planning A, 33 (1), 97-119. 
Hao, R., \& Wei, Z. (2010). Fundamental causes of inland-coastal income inequality in post-reform China. The Annals of Regional Science, 45 (1), 181-206.

He, C., Wei, Y. H. D., \& Xie, X. (2008). Globalization, institutional change, and industrial location: Economic transition and industrial concentration in China. Regional Studies, 42 (7), 923-945.

Jacobs, J. (1969). The economy of cities. New York: Vintage.

Kanbur, R., \& Venables, A. J. (2005). Rising spatial disparities and development Helsinki: Number 3 in United Nations University Policy Brief.

Krugman, P. (1991). Increasing Returns and Economic Geography. The Journal of Political Economy, 99 (3), 483-499.

Krugman, P. (1999). The role of geography in development. International Regional Science Review, 22 (2), 142-161.

Krugman, P. (2011). The new economic geography, now middle-aged. Regional Studies, 45 (1), 1-7.

Kuznets, S. (1955). Economic Growth and Income Inequality. The American Economic Review, 45 (1), 1-28.

Lessmann, C. (2013). Foreign direct investment and regional inequality: A panel data analysis. China Economic Review, 24 (C), 129-149.

Lessmann, C. (2014). Spatial inequality and development-Is there an inverted-U relationship? Journal of Development Economics, 106, 35-51.

Li, C., \& Gibson, J. (2013). Rising regional inequality in China: Fact or artifact? World Development, 47, 16-29.

Li, G., \& Fang, C. (2014). Analyzing the multi-mechanism of regional inequality in China. The Annals of Regional Science, 52 (1), 155-182.

Li, Y., \& Wei, Y. H. D. (2010). The spatial-temporal hierarchy of regional inequality of Chinaq. Applied Geography, 30, 303-316.

Li, Y., \& Wei, Y. H. D. (2014). Multidimensional Inequalities in Health Care Distribution in Provincial China: a Case Study of Henan Province. Tijdschrift voor economische en sociale geografie [Journal of Economic and Social Geography], 105 (1), 91-106.

Liao, H. F., \& Chan, R. C. (2011). Industrial relocation of Hong Kong manufacturing firms: towards an expanding industrial space beyond the Pearl River Delta. GeoJournal, 76 (6), 623-639.

Liao, H. F. F., \& Wei, Y. H. D. (2012). Dynamics, space, and regional inequality in provincial China: A case study of Guangdong Province. Applied Geography, 35 (1), 71-83.

Lin, G. C. S. (1997). Red capitalism in South China: Growth and development of the Pearl River Delta. Vancouver: UBC press.

Lin, G. C. S. (2009). Scaling-up regional development in globalizing China: Local capital accumulation, land-centred politics, and reproduction of space. Regional Studies, 43 (3), 429-447.

Liu, Y., \& Yang, C. (2013). Strategic coupling of local firms in global production networks: the rise of the home appliance industry in Shunde, China. Eurasian Geography and Economics, 54 (4), 444-463.

Lu, L., \& Wei, Y. H. D. (2007). Domesticating globalisation, new economic spaces and regional polarisation in Guangdong Province, China. Tijdschrift voor 
economische en sociale geografie [Journal of Economic and Social Geography], 98 (2), 225-244.

Lu, M., \& Wang, E. (2002). Forging Ahead and Falling Behind: Changing Regional Inequalities in Post-reform China. Growth and Change, 33 (1), 42-71.

Martin, R., \& Sunley, P. (1998). Slow Convergence? The New Endogenous Growth Theory and Regional Development. Economic geography, 74 (3), 201-227.

Maza, A., \& Villaverde, J. (2009). Spatial effects on provincial convergence and income distribution in Spain: 1985-2003. Tijdschrift voor economische en sociale geografie [Journal of Economic and Social Geography], 100 (3), 316-331.

Ng, L. F. Y., \& Tuan, C. (2003). Location decisions of manufacturing FDI in China: Implications of China's WTO accession. Journal of Asian Economics, 14(1), 5172.

Oi, J. C. (1995). The role of the local state in China's transitional economy. The China Quarterly, 144, 1132-1149.

Patuelli, R., Griffith, D. A., Tiefelsdorf, M., \& Nijkamp, P. (2011). Spatial filtering and eigenvector stability: Space-time models for German unemployment data. International Regional Science Review, 34 (2), 253-280.

Petrakos, G., Rodríguez-Pose, A., \& Rovolis, A. (2005). Growth, integration, and regional disparities in the European Union. Environment and Planning A, 37 (10), $1837-1855$.

Scott, A., \& Storper, M. (2003). Regions, Globalization, Development. Regional Studies, 37 (6-7), 579-593.

Thayn, J. B., \& Simanis, J. M. (2013). Accounting for spatial autocorrelation in linear regression models using spatial filtering with eigenvectors. Annals of the Association of American Geographers, 103 (1), 47-66.

Tiefelsdorf, M., \& Griffith, D. A. (2007). Semiparametric filtering of spatial autocorrelation: the eigenvector approach. Environment and Planning A, 39 (5), 1193-1221.

Wang, E. (2010). Fiscal decentralization and revenue/expenditure disparities in China. Eurasian Geography and Economics, 51 (6), 744-766.

Wei, Y. H. D. (1999). Regional inequality in China. Progress in Human Geography, 23 (1), 49-59.

Wei, Y. H. D. (2000). Regional Development in China: States, Globalization, and Inequality. London and New York: Routledge.

Wei, Y. H. D. (2002). Multiscale and multimechanisms of regional inequality in China: implications for regional policy. Journal of Contemporary China, 11 (30), 109124.

Wei, Y. H. D. (2004). Trajectories of ownership transformation in China: Implications for uneven regional development. Eurasian Geography and Economics, 45 (2), 90-113.

Wei, Y. H. D., \& Ma, J. C. L. (1994). Regional changes of capital construction investment in China. Scientia Geographica Sinica, 14 (1), 22-29.

Wei, Y. H. D., \& Kim, S. (2002). Widening inter-county inequality in Jiangsu province, China, 1950-95. Journal of Development Studies, 38 (6), 142-164. 
Wei, Y. H. D., \& Ye, X. (2004). Regional inequality in China: A case study of Zhejiang province. Tijdschrift voor economische en sociale geografie [Journal of Economic and Social Geography], 95 (1), 44-60.

Wei, Y. H. D., \& Ye, X. (2009). Beyond convergence: Space, scale, and regional inequality in China. Tijdschrift voor economische en sociale geografie [Journal of Economic and Social Geography], 100 (1), 59-80.

Wei, Y. H. D., Yu, D., \& Chen, X. (2011). Scale, agglomeration, and regional inequality in provincial China. Tijdschrift voor economische en sociale geografie [Journal of Economic and Social Geography], 102 (4), 406-425.

Williamson, J. G. (1965). Regional inequality and the process of national development: a description of the patterns. Economic development and cultural change, 13 (4), 3 45.

Xu, J., \& Yeh, A. G. O. (2005). City repositioning and competitiveness building in regional development: new development strategies in Guangzhou, China. International Journal of Urban and Regional Research, 29 (2), 283-308.

Ye, X., \& Wei, Y. H. D. (2005). Geospatial analysis of regional development in China: the case of Zhejiang Province and the Wenzhou model. Eurasian Geography and Economics, 46 (6), 445-464.

Yu, D., \& Wei, Y. H. D. (2008). Spatial data analysis of regional development in Greater Beijing, China, in a GIS environment. Papers in Regional Science, 87 (1), 97-117.

Yuan, Y., \& Wu, F. (2013). Regional Social Inequalities and Social Deprivation in Guangdong Province, China. Growth and Change, 44 (1), 149-167.

Yue, W., Zhang, Y., Ye, X., Cheng, Y., \& Leipnik, M. R. (2014). Dynamics of MultiScale Intra-Provincial Regional Inequality in Zhejiang, China. Sustainability, 6 (9), 5763-5784.

Zhao, S. X., Chan, R. C., \& Chan, N. Y. M. (2012). Spatial polarization and dynamic pathways of foreign direct investment in China 1990-2009. Geoforum, 43 (4), 836-850. 


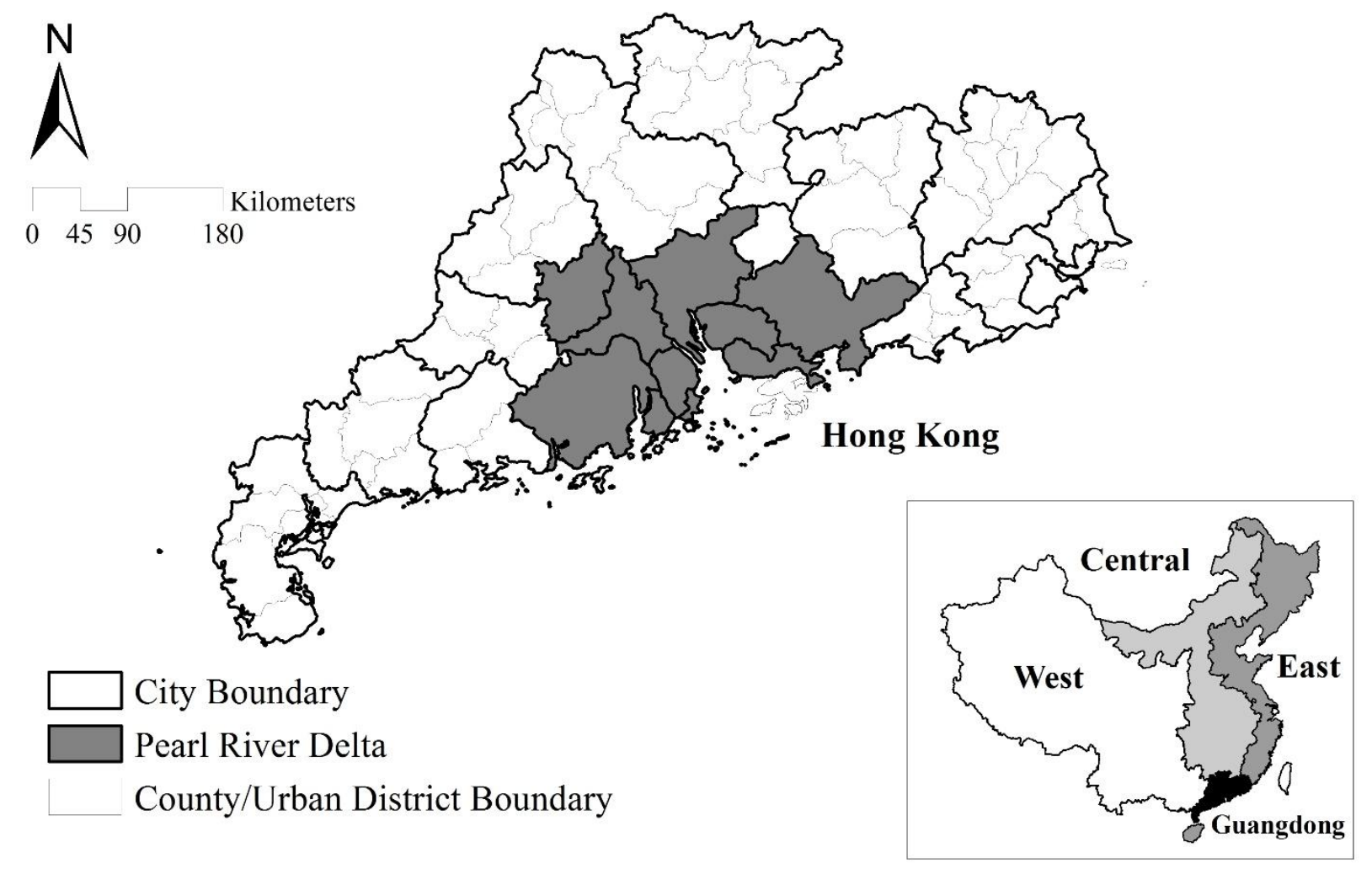

Fig. 1. Location of Guangdong in China 

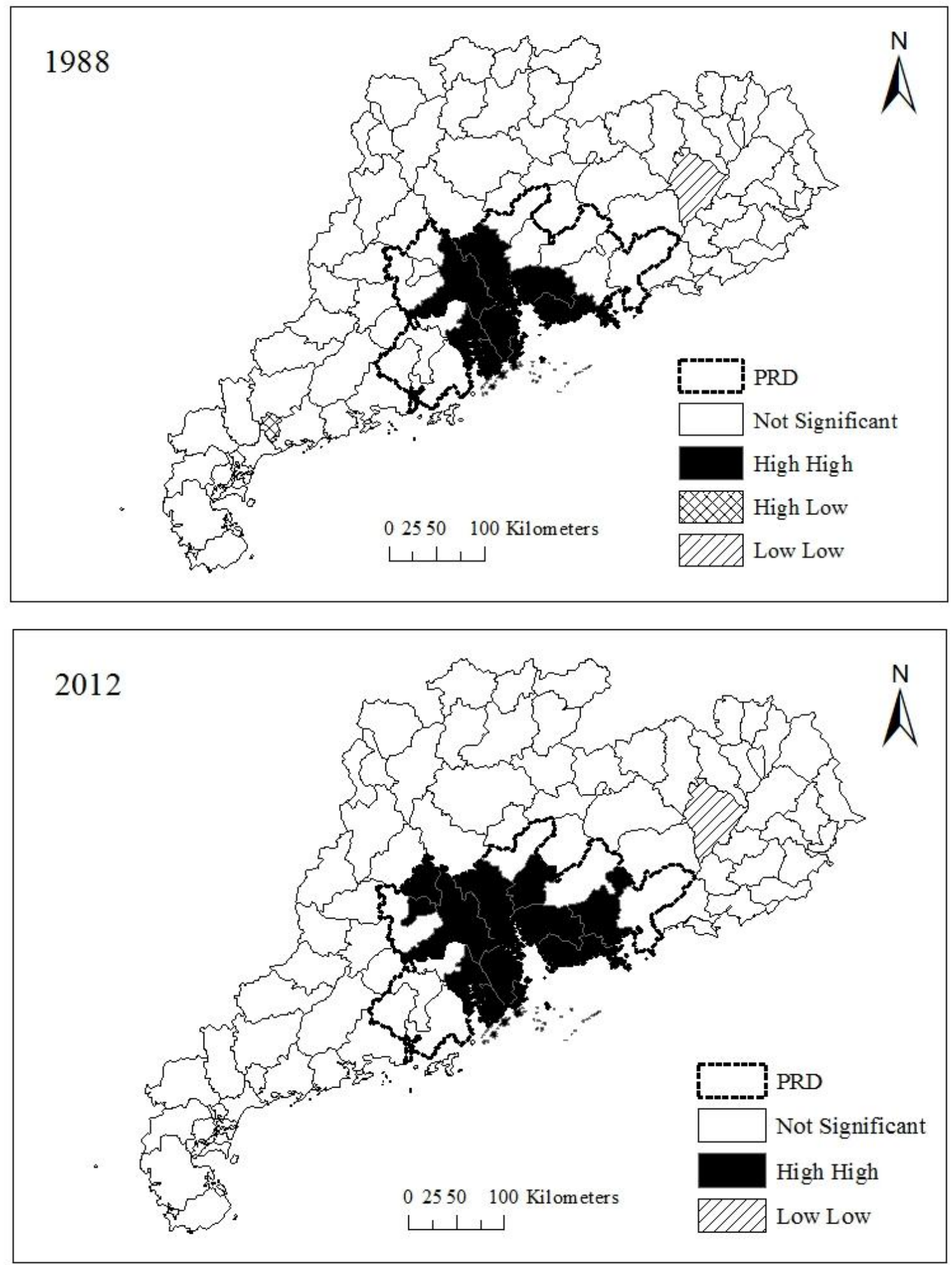

Fig. 2. Local Moran's I of county-level GDP per capita in Guangdong, 1988, 2012 

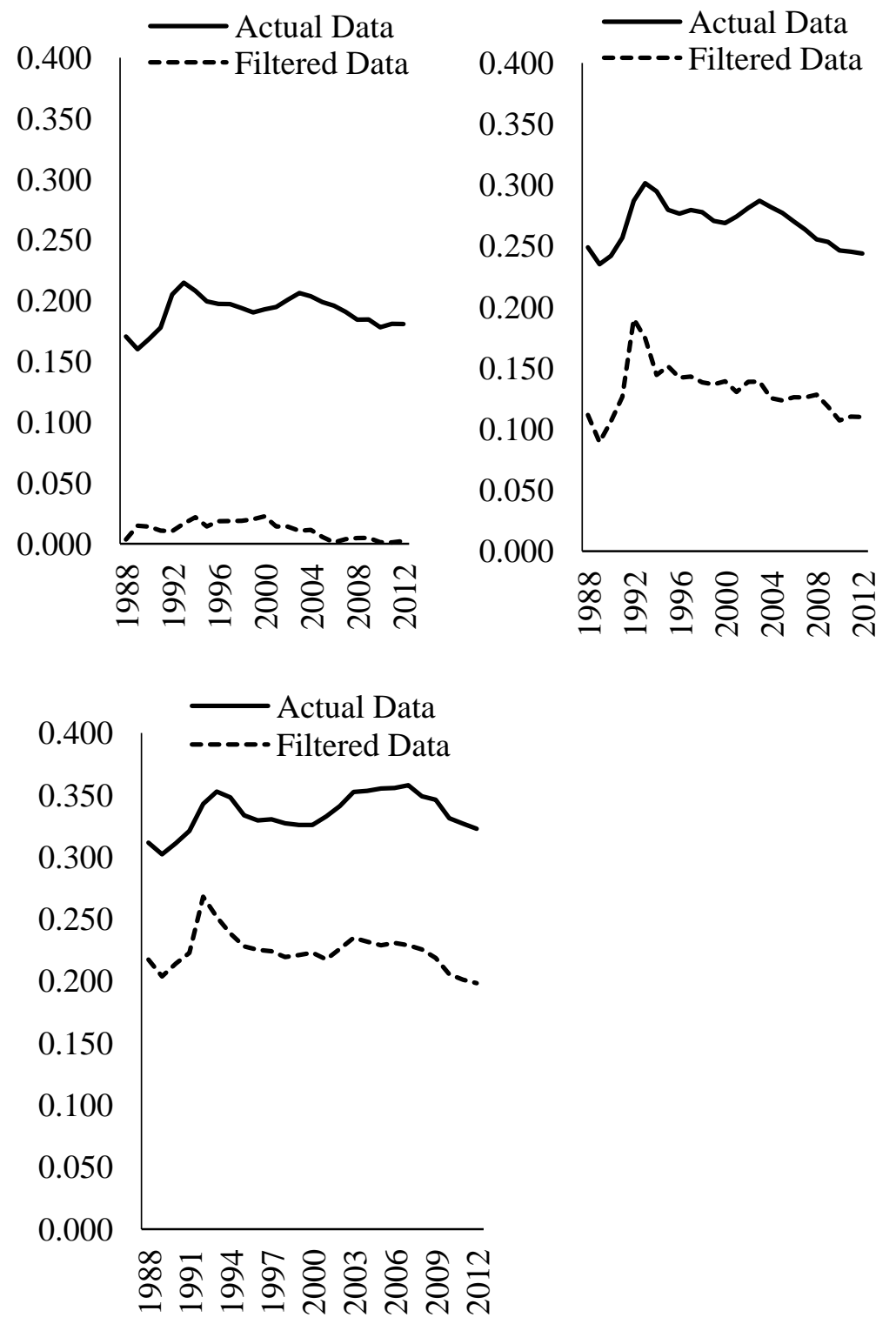

a) inter-regional inequalities b) inter-municipality inequalities c) inter-county inequalities

Fig. 3. Multiscale inequalities (measured by WCV) with/without spatial filters in Guangdong 

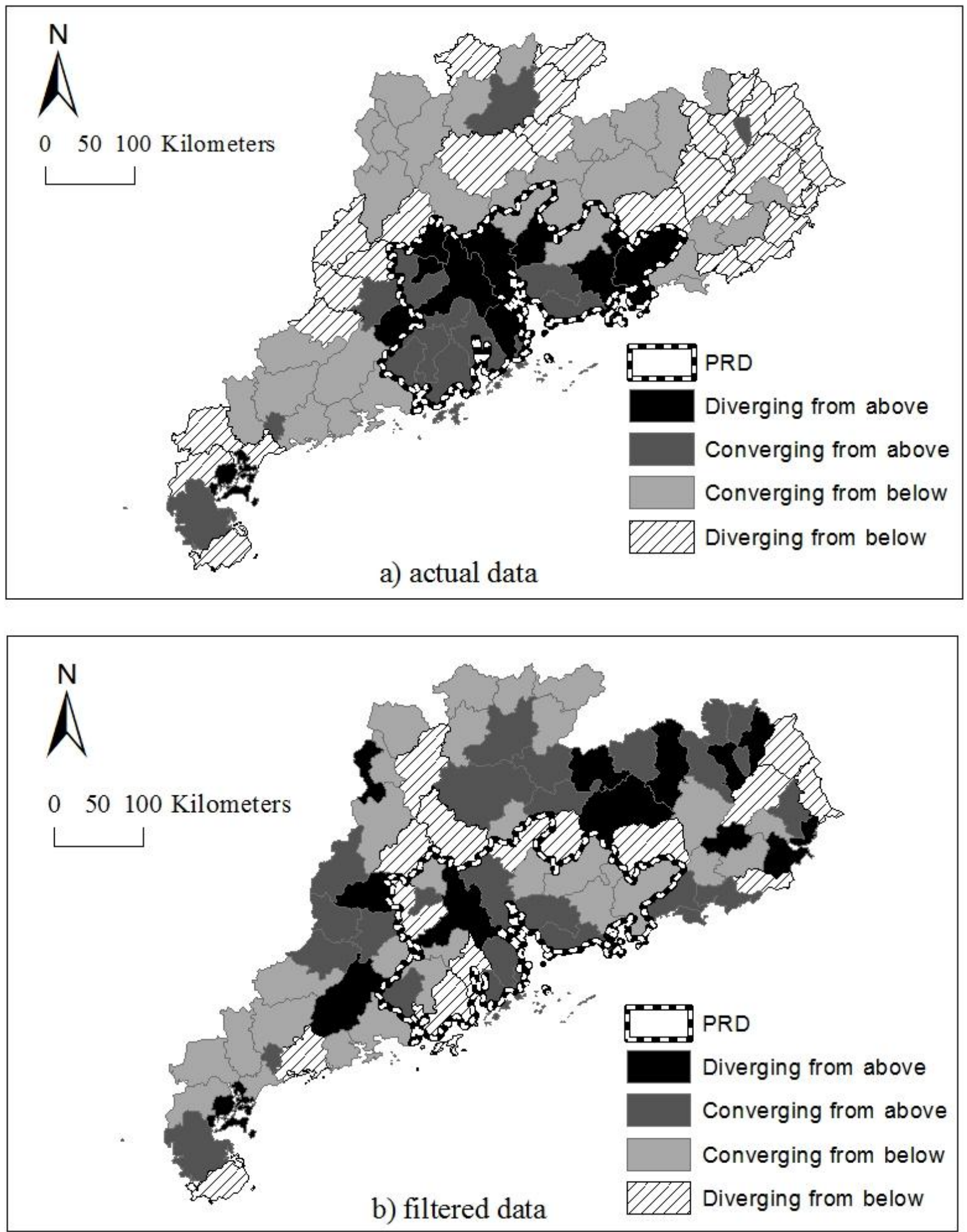

Fig. 4. Changing county-level GDP per capita in Guangdong, 1988-2012 

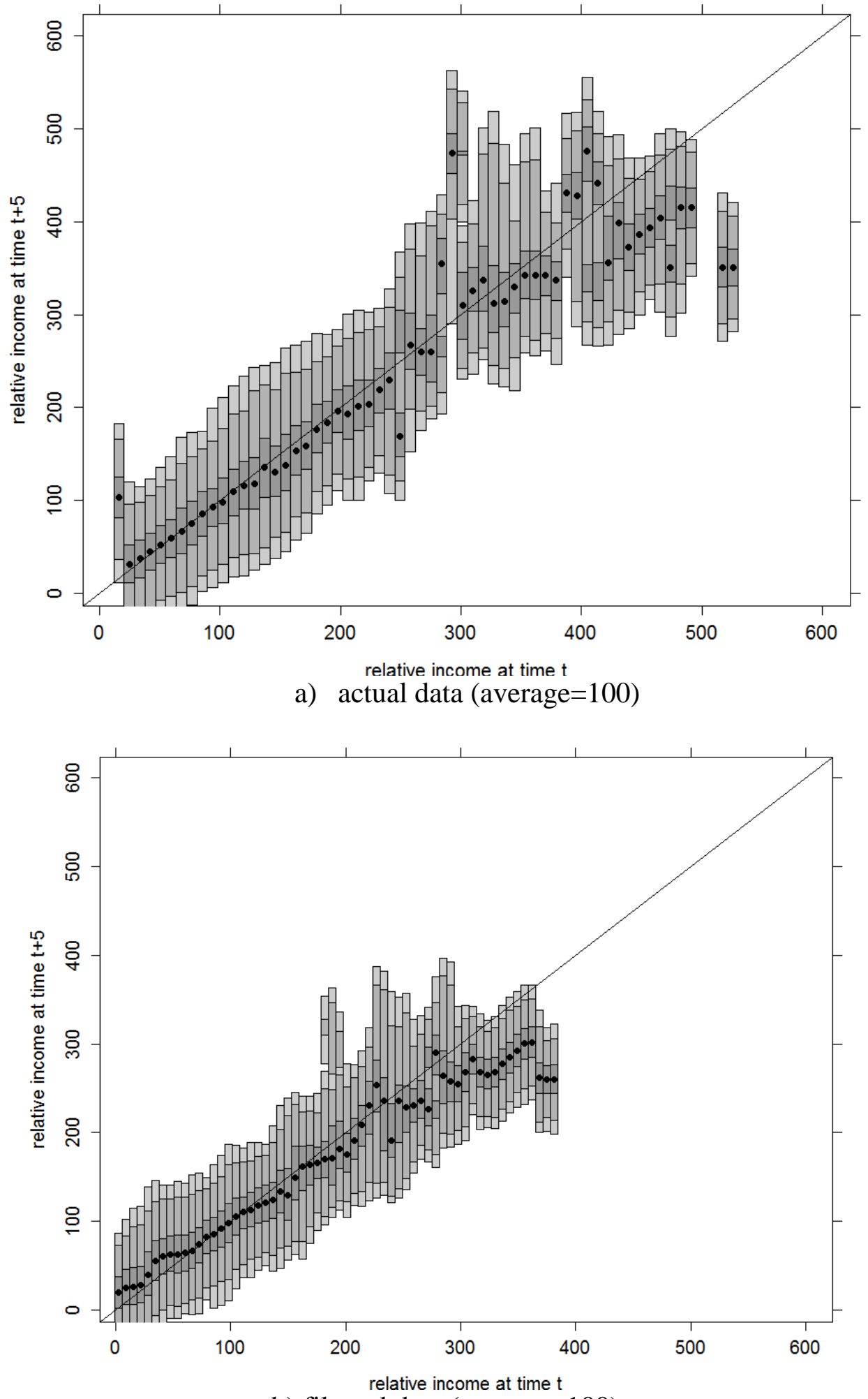

b) filtered data (average $=100)$

Fig. 5. Stochastic kernel density estimation of changing county-level GDP per capita 

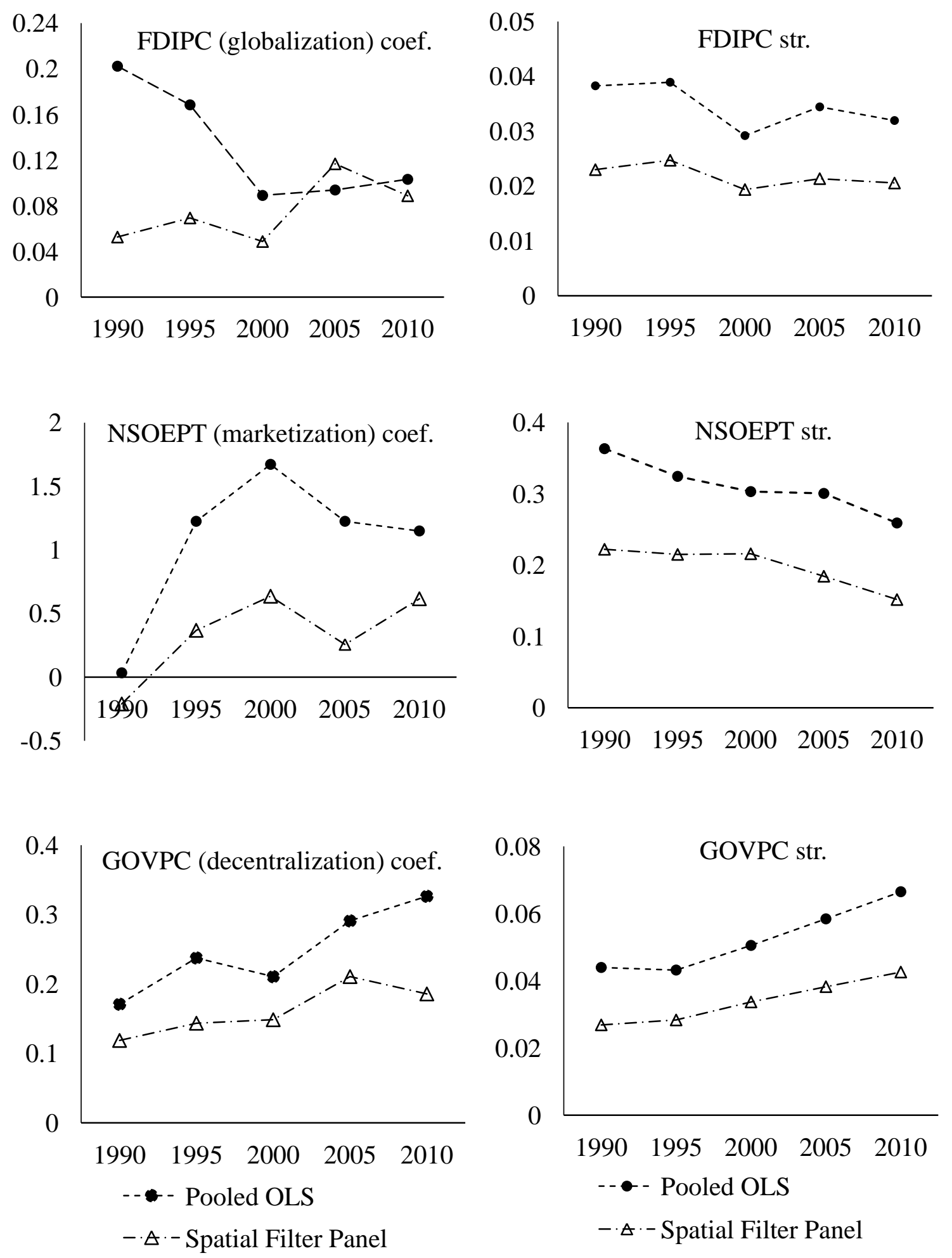

Fig. 6. Temporally varying coefficients of multi-mechanism derived from space-time models 

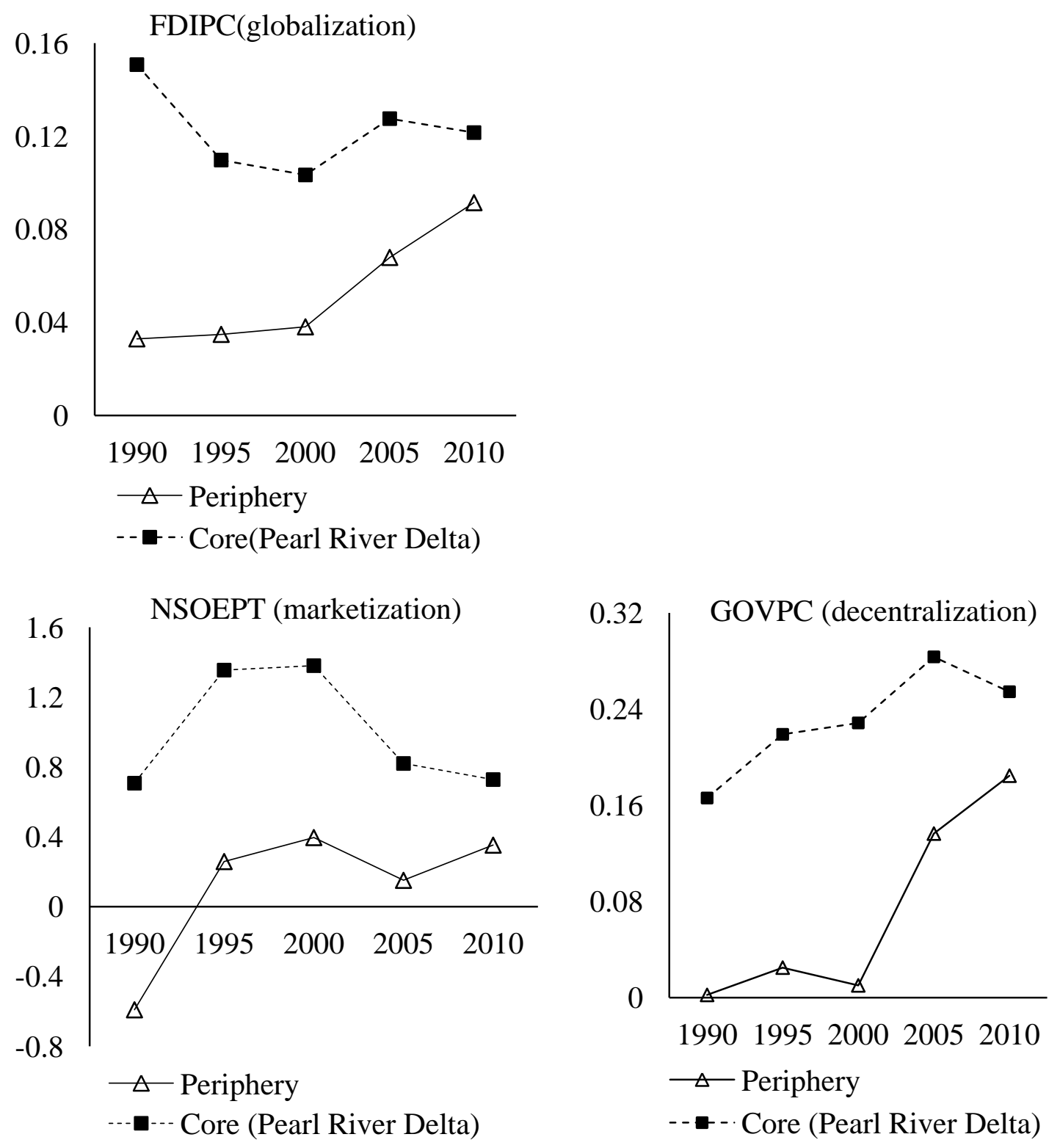

Fig. 7. Spatially and temporally varying coefficients of multi-mechanism derived from space-time models 
Table 1. Core-periphery structure in Guangdong

\begin{tabular}{|c|c|c|c|c|c|c|}
\hline & \multirow{2}{*}{\multicolumn{2}{|c|}{ Guangdong }} & \multicolumn{4}{|c|}{ As percentage of Guangdong } \\
\hline & & & \multicolumn{2}{|c|}{ Pearl River Delta } & \multicolumn{2}{|c|}{ Periphery } \\
\hline & 1990 & 2012 & 1990 & 2012 & 1990 & 2012 \\
\hline Population (million) & 63.5 & 105.9 & 30.4 & 53.3 & 69.6 & 46.7 \\
\hline Land area $\left(\mathrm{sq} \mathrm{km}^{2}\right)$ & 179,612 & 179,612 & 30.5 & 30.5 & 69.5 & 69.5 \\
\hline GDP (billion yuan) & 155.9 & 5706.8 & 55.5 & 76.6 & 44.5 & 23.4 \\
\hline $\begin{array}{l}\text { Investments in fixed assets } \\
\text { (billion yuan) }\end{array}$ & 38.1 & 1930.8 & 69.3 & 64.1 & 30.7 & 35.9 \\
\hline Exports (US\$ billion) & 22.2 & 574.1 & 100.0 & 88.2 & 0.0 & 11.8 \\
\hline FDI (US \$billion) & 1.5 & 23.5 & 84.7 & 82.8 & 15.3 & 17.2 \\
\hline
\end{tabular}

Source: GSB, 2014 
Table 2. Z-scores of Moran's I

\begin{tabular}{llllll}
\hline Year & Contiguity & $\begin{array}{l}\text { Inverse } \\
\text { distance }\end{array}$ & $\begin{array}{l}\text { Inverse distance } \\
\text { square }\end{array}$ & $\begin{array}{l}\text { Fixed distance } \\
\text { band }\end{array}$ & $\begin{array}{l}\text { Zone of } \\
\text { indifference }\end{array}$ \\
\hline 1988 & 6.278 & 4.296 & 2.550 & 4.769 & 4.771 \\
1990 & 6.066 & 4.053 & 2.370 & 4.508 & 4.510 \\
1995 & 6.251 & 4.894 & 2.913 & 5.472 & 5.475 \\
2000 & 6.205 & 4.848 & 2.913 & 5.440 & 5.442 \\
2001 & 6.238 & 4.798 & 2.871 & 5.397 & 5.399 \\
2002 & 6.237 & 4.697 & 2.804 & 5.279 & 5.281 \\
2003 & 6.177 & 4.583 & 2.741 & 5.134 & 5.137 \\
2004 & 6.257 & 4.659 & 2.817 & 5.187 & 5.189 \\
2005 & 6.468 & 4.744 & 2.834 & 5.294 & 5.296 \\
2006 & 6.629 & 4.828 & 2.855 & 5.402 & 5.404 \\
2007 & 6.958 & 4.871 & 2.848 & 5.467 & 5.468 \\
2008 & 7.228 & 4.943 & 2.888 & 5.572 & 5.574 \\
2009 & 7.539 & 5.127 & 3.004 & 5.775 & 5.776 \\
2010 & 7.390 & 4.848 & 3.110 & 5.897 & 5.898 \\
2011 & 7.502 & 4.798 & 3.115 & 5.906 & 5.908 \\
2012 & 7.509 & 4.697 & 3.129 & 5.893 & 5.895 \\
\hline
\end{tabular}


Table 3. Moran's $I$ of actual and spatially filtered county-level GDP per capita, 19882012

\begin{tabular}{lllllll}
\hline & \multicolumn{3}{l}{ Non-filtered data } & \multicolumn{4}{l}{ Filtered data } \\
Year & Moran's $I$ & z-value & p-value & Moran's $I$ & z-value & p-value \\
\hline 1988 & 0.457 & 6.466 & 0.000 & -0.053 & -0.559 & 0.576 \\
1990 & 0.449 & 6.327 & 0.000 & -0.096 & -1.131 & 0.258 \\
1995 & 0.461 & 6.593 & 0.000 & -0.105 & -1.281 & 0.200 \\
2000 & 0.461 & 6.500 & 0.000 & -0.093 & -1.096 & 0.273 \\
2001 & 0.468 & 6.589 & 0.000 & -0.149 & -1.857 & 0.063 \\
2002 & 0.469 & 6.639 & 0.000 & -0.131 & -1.622 & 0.105 \\
2003 & 0.466 & 6.608 & 0.000 & -0.136 & -1.687 & 0.092 \\
2004 & 0.472 & 6.679 & 0.000 & -0.148 & -1.843 & 0.065 \\
2005 & 0.485 & 6.832 & 0.000 & -0.144 & -1.788 & 0.074 \\
2006 & 0.492 & 6.918 & 0.000 & -0.132 & -1.617 & 0.106 \\
2007 & 0.508 & 7.101 & 0.000 & -0.123 & -1.485 & 0.137 \\
2008 & 0.515 & 7.182 & 0.000 & -0.101 & -1.186 & 0.236 \\
2009 & 0.526 & 7.324 & 0.000 & -0.108 & -1.280 & 0.201 \\
2010 & 0.527 & 7.321 & 0.000 & -0.117 & -1.401 & 0.161 \\
2011 & 0.535 & 7.420 & 0.000 & -0.112 & -1.338 & 0.181 \\
2012 & 0.536 & 7.433 & 0.000 & -0.118 & -1.415 & 0.157 \\
\hline
\end{tabular}


Table 4. Regional inequality with and without spatial filters

\begin{tabular}{|c|c|c|c|c|c|c|}
\hline \multirow{2}{*}{ Year } & \multicolumn{3}{|l|}{ Theil } & \multicolumn{3}{|l|}{ GINI } \\
\hline & $\begin{array}{l}\text { Non- } \\
\text { Filtered }\end{array}$ & Filtered & $\begin{array}{l}\% \text { of } \\
\text { inequality } \\
\text { explained by } \\
\text { spatial } \\
\text { dependence }\end{array}$ & $\begin{array}{l}\text { Non- } \\
\text { Filtered }\end{array}$ & Filtered & $\begin{array}{l}\% \text { of } \\
\text { inequality } \\
\text { explained by } \\
\text { spatial } \\
\text { dependence }\end{array}$ \\
\hline \multicolumn{7}{|c|}{ Interregional } \\
\hline 1988 & 0.064 & 0.000 & 99.05 & 0.170 & 0.004 & 97.93 \\
\hline 1995 & 0.087 & 0.000 & 99.04 & 0.199 & 0.014 & 92.85 \\
\hline 2000 & 0.082 & 0.001 & 98.52 & 0.193 & 0.023 & 88.28 \\
\hline 2005 & 0.087 & 0.001 & 99.02 & 0.199 & 0.006 & 97.22 \\
\hline 2010 & 0.070 & 0.000 & 98.99 & 0.178 & 0.001 & 98.27 \\
\hline \multicolumn{7}{|c|}{ Intermunicipality } \\
\hline 1988 & 0.124 & 0.034 & 72.88 & 0.249 & 0.112 & 55.19 \\
\hline 1995 & 0.158 & 0.056 & 64.45 & 0.280 & 0.151 & 45.85 \\
\hline 2000 & 0.138 & 0.046 & 66.94 & 0.269 & 0.139 & 48.22 \\
\hline 2005 & 0.159 & 0.037 & 76.62 & 0.277 & 0.123 & 55.47 \\
\hline 2010 & 0.125 & 0.027 & 78.61 & 0.246 & 0.107 & 56.50 \\
\hline \multicolumn{7}{|c|}{ Intercounty } \\
\hline 1988 & 0.176 & 0.088 & 49.99 & 0.311 & 0.217 & 30.24 \\
\hline 1995 & 0.199 & 0.098 & 50.54 & 0.334 & 0.228 & 31.66 \\
\hline 2000 & 0.184 & 0.089 & 51.52 & 0.326 & 0.223 & 31.59 \\
\hline 2005 & 0.222 & 0.094 & 57.82 & 0.355 & 0.229 & 36.05 \\
\hline 2010 & 0.187 & 0.070 & 62.53 & 0.331 & 0.205 & 38.01 \\
\hline
\end{tabular}


Table 5. Spatial filtering panel regression and selected eigenvectors, 1990-2010

\begin{tabular}{|c|c|c|c|c|c|}
\hline \multirow[b]{2}{*}{ Year } & \multicolumn{2}{|l|}{ OLS } & \multicolumn{3}{|l|}{ Spatial filtering } \\
\hline & $\begin{array}{l}\text { Pesudo } \\
\mathrm{R}^{2}\end{array}$ & $\begin{array}{l}\text { Moran's I } \\
\text { for } \\
\text { residuals }\end{array}$ & Selected Eigenvectors & $\begin{array}{l}\text { Pesud } \\
\mathrm{o}^{2}\end{array}$ & $\begin{array}{l}\text { Moran's I for } \\
\text { residuals }\end{array}$ \\
\hline 1990 & 0.662 & 0.462 & $\begin{array}{l}\text { E1, E2, E3, E4, E7, E9, } \\
\text { E10, E11, E12, E19, E21 }\end{array}$ & 0.910 & -0.145 \\
\hline 1995 & 0.794 & 0.057 & $\begin{array}{l}\text { E3, E4, E7, E8, E9, E10, } \\
\text { E11, E12, E15, E16, E17 }\end{array}$ & 0.958 & -0.183 \\
\hline 2000 & 0.730 & 0.153 & $\begin{array}{l}\text { E3, E4, E5, E7, E8, E9, } \\
\text { E10, E11, E12, E13 }\end{array}$ & 0.959 & -0.195 \\
\hline 2005 & 0.706 & 0.188 & $\begin{array}{l}\text { E3, E4, E7, E8, E9, E10, } \\
\text { E11, E12,E13, E15 }\end{array}$ & 0.962 & -0.046 \\
\hline 2010 & 0.761 & 0.160 & $\begin{array}{l}\text { E3, E7, E8, E10, E11, E12, } \\
\text { E13, E15, E20, E21 }\end{array}$ & 0.958 & -0.164 \\
\hline
\end{tabular}

Table 6. Results of spatial filtering panel regression and pooled OLS regression models

\begin{tabular}{|c|c|c|c|c|c|c|c|}
\hline & \multicolumn{3}{|c|}{ Pooled OLS } & \multicolumn{4}{|c|}{ Spatial filtering panel } \\
\hline & Coef. & Sig. & T-value & VIF & Coef. & Sig. & T-value \\
\hline FDIPC & 0.014 & & 0.876 & 2.116 & 0.061 & $* * *$ & 5.313 \\
\hline NSOEPT & 1.103 & $* * *$ & 7.778 & 1.758 & 0.528 & *** & 5.616 \\
\hline GOVPC & 0.102 & **** & 4.010 & 1.518 & 0.078 & *** & 3.479 \\
\hline FIXPC & 0.147 & **** & 11.906 & 2.211 & 0.061 & *** & 3.924 \\
\hline Urban & 0.996 & $* * *$ & 6.568 & 2.432 & 0.565 & $* * *$ & 4.423 \\
\hline Constant & 6.042 & $* * *$ & 82.409 & & 6.674 & $* * *$ & 85.490 \\
\hline BIC & 349.347 & & & & 104.03 & & \\
\hline Adjust R2 & 0.772 & & Log likel & od ratic & & $<0.00$ & \\
\hline
\end{tabular}

Note: *** Significant at $1 \%$ level. 